\title{
Letter
}

\section{In situ ESEM observation of melting silver and Inconel on an $\mathrm{Al}_{2} \mathrm{O}_{3}$ powder bed}

\author{
Simon Fischer ${ }^{1}$, Katja Lemster ${ }^{1}$, Ralf Kaegi ${ }^{1}$, Jakob Kuebler ${ }^{1, *}$ and Bernard Grobéty ${ }^{2}$ \\ ${ }^{1}$ EMPA, Swiss Federal Laboratories for Materials Testing and Research, $\mathrm{CH}-8600$ Dübendorf and ${ }^{2}$ Department \\ of Geosciences, University of Fribourg, CH-1700 Fribourg, Switzerland \\ *To whom correspondence should be addressed. E-mail: jakob.kuebler@empa.ch
}





\title{
Letter
}

\section{In situ ESEM observation of melting silver and Inconel on an $\mathrm{Al}_{2} \mathrm{O}_{3}$ powder bed}

\author{
Simon Fischer ${ }^{1}$, Katja Lemster ${ }^{1}$, Ralf Kaegi ${ }^{1}$, Jakob Kuebler ${ }^{1}{ }^{*}$ and Bernard Grobéty ${ }^{2}$ \\ ${ }^{1}$ EMPA, Swiss Federal Laboratories for Materials Testing and Research, $\mathrm{CH}-8600$ Dübendorf and ${ }^{2}$ Department \\ of Geosciences, University of Fribourg, CH-1700 Fribourg, Switzerland \\ *To whom correspondence should be addressed. E-mail: jakob.kuebler@empa.ch
}

$\begin{array}{ll}\text { Abstract } & \left.\begin{array}{l}\text { A hot stage in an environmental scanning electron microscope (ESEM) } \\ \text { was used for in situ infiltration experiments. Pressureless infiltration of a } \\ \text { porous Ti-activated } \mathrm{Al}_{2} \mathrm{O}_{3} \text { preform has been investigated at temperatures } \\ \text { up to } 1530^{\circ} \mathrm{C} \text { under two atmospheres }\left(\mathrm{He} \text { and } \mathrm{H}_{2} \mathrm{O}(\mathrm{g})\right.\end{array}\right) \text {. A brief description } \\ \text { of the operating and the experimental set-up is given. Silver and Inconel } \\ \text { (Ni superalloy) infiltration experiments demonstrate the in situ potential } \\ \text { of the ESEM at temperatures up to } 1500^{\circ} \mathrm{C} \text {. } \\ \text { Keywords } \\ \text { ESEM, hot stage, in situ high-temperature imaging, Ti-activated } \mathrm{Al}_{2} \mathrm{O}_{3} \\ \text { Wetting process }\end{array}$

The production of metal matrix composites (MMC) by pressureless Ti-activated melt infiltration is a technique used in addition to powder metallurgical and pressure-induced processes. One of the major problems of infiltration techniques in general is the non-wetting behaviour of liquid metals on ceramic surfaces. The use of an activator material, like titanium (Ti), overcomes this difficulty. Addition of $\mathrm{Ti}$ enables non-wetting liquid metals to infiltrate a ceramic matrix. While it is possible to achieve good quality MMCs by activated melt infiltration, a scientific understanding of the mechanism of this process is still lacking [1-5].

Pressureless melt infiltration carried out under high vacuum or in an inert gas atmosphere allows only for examination of wetting behaviour after cooling to room temperature; therefore, no information is obtained about the process itself. The purpose of the current experiments was to observe the dynamic processes of surface wetting and subsequent infiltration in situ using a commercially available hot stage for an environmental scanning electron microscope (ESEM). The ESEM technique allows the investigation of non-conductive samples without any coating [6]. This was a prerequisite for this study.

For the combination of oxide ceramics (e.g. $\mathrm{Al}_{2} \mathrm{O}_{3}$ ) with high-melting alloys, such as steel and Ni-base alloys, infiltration temperatures as high as $1400-1600^{\circ} \mathrm{C}$ are needed $[4,5]$. The combination of alumina and Inconel (melting point of $1350^{\circ} \mathrm{C}$ ) with infiltration temperatures of $\sim 1450^{\circ} \mathrm{C}$ is still within the temperature range of the hot stage, but questions remained concerning the imaging possibilities at such high temperatures.

In this study, an ESEM-FEG XL-30 (FEI) was used at $20 \mathrm{kV}$ acceleration voltage and $19 \mathrm{~mm}$ working distance. Because of mechanical constraints of the hot stage, the working distance could not be reduced. A gaseous secondary electron detector (GSED) was used for image formation with $\mathrm{H}_{2} \mathrm{O}_{(\mathrm{g})}$ or He as the imaging gases. In the ESEM, the gas is ionized by the electron beam. The positive ions are used to suppress charging of the sample. The negative charges are accelerated towards the detector electrode. The original secondary electron signal is amplified by producing an avalanche of gaseous electrons [7]. A heat shield was inserted between the detector and the sample to protect the detector from heat radiation. The energy-dispersive X-ray (EDX) detector was retracted for the same reason and, thus, no elemental analysis was possible during in situ experiments at high temperatures. Therefore, all observed phases were characterized by EDX after cooling.

The hot-stage system (FP6754/PW6753; Fig. 1) included a furnace with the ability to heat small samples to temperatures $>1500^{\circ} \mathrm{C}$. It was mounted directly on a 3-axis sample stage. The inner part of the hot stage contained the stage heater assembly composed of a heating element, thermocouple and connectors. The stage heater was a coiled tungsten wire sheathed in alumina, integrated in a hollow alumina cylinder. The thermocouple was located inside the heater. The crucible with the sample was introduced into the 


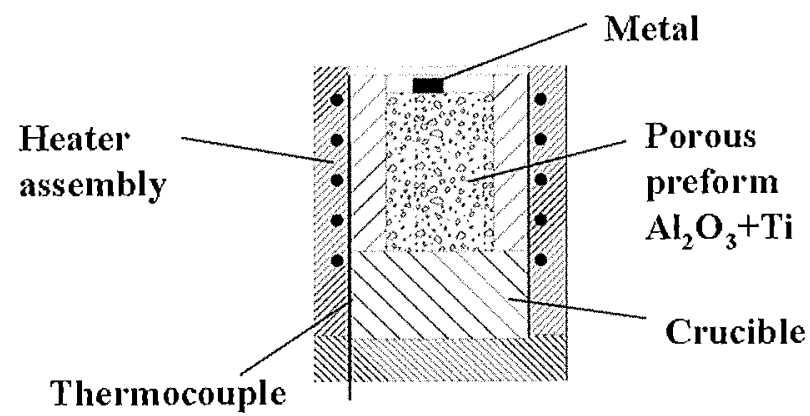

Fig. 1 Experimental set-up. Inner part of hot stage with sample (preform diameter $4 \mathrm{~mm}$ ).

Table 1. Materials used

\begin{tabular}{|c|c|c|}
\hline $\begin{array}{l}\mathrm{Al}_{2} \mathrm{O}_{3} \\
\text { (fused alumina) }\end{array}$ & $\begin{array}{l}99.8 \% \text { purity, } \\
\mathrm{d}_{50} 90-125 \mu \mathrm{m}\end{array}$ & $\begin{array}{l}\text { Particles } \\
\text { (Treibacher Schleifmittel, } \\
\text { Laufenburg, Germany) }\end{array}$ \\
\hline Titanium & $99.23 \%$ purity & $\begin{array}{l}\text { Powdered } \\
\text { form }\end{array}$ \\
\hline Silver & $99.9 \%$ purity & $\begin{array}{l}\text { Pieces (Alfa Aesar, } \\
\text { Johmson Matthey, } \\
\text { Karlsruhe, Germany) }\end{array}$ \\
\hline Inconel 625 & $\begin{array}{l}\mathrm{Ni}_{>58} \mathrm{Cr}_{20-23} \mathrm{Mo}_{8-10} \\
\mathrm{Fe}_{5} \mathrm{Nb}_{3.15-4.25} \mathrm{Ti}_{<0.4}\end{array}$ & $\begin{array}{l}\text { Pieces } \\
\text { (Bibus Metals, } \\
\text { Wallisellen, Switzerland) }\end{array}$ \\
\hline
\end{tabular}

Table 2. The ESEM operating conditions

\begin{tabular}{|c|c|c|}
\hline & Silver & Inconel 625 \\
\hline Detector & \multicolumn{2}{|c|}{$\begin{array}{l}\text { GSED with } 500 \mu \mathrm{m} \text { pressure-limiting } \\
\text { aperture }\end{array}$} \\
\hline Atmosphere gas & $\mathrm{He}$ & $\mathrm{H}_{2} \mathrm{O}_{(\mathrm{g})}$ \\
\hline Gas pressure & 4 Torr & 2 Torr \\
\hline $\begin{array}{l}\text { Max. infiltration } \\
\text { temperature }\end{array}$ & $1300^{\circ} \mathrm{C}$ & $1530^{\circ} \mathrm{C}$ \\
\hline Ramping & \multicolumn{2}{|c|}{$\begin{array}{l}10-40^{\circ} \mathrm{C} \text { min } \\
\text { afterwards manual ramping at }<10^{\circ} \mathrm{C} \text { min }^{-1}\end{array}$} \\
\hline
\end{tabular}

central hole ( $\varnothing 8 \mathrm{~mm}$ ) of the heater so that the thermocouple was situated between the heater and the crucible exterior. The hot stage was loaded with the prepared crucible containing the porous $\mathrm{Al}_{2} \mathrm{O}_{3}$ preform.

An alumina crucible instead of graphite was used to avoid contamination of the sample by carbon. Carbon reacts with Ti to form TiC, which alters the effectiveness of the activator. The crucible had an alumina wash applied to improve the contact between the crucible and the sample heater, resulting in higher thermal conductivity. The preform was made by compacting $\mathrm{Al}_{2} \mathrm{O}_{3}$ particles, activator and organic binder (Table 1). A piece of the infiltrate metal (Fig. 1), previously separated from its oxide layer and cleaned with acetone in an ultrasonic bath, was placed on top of the preform.

The ESEM operating conditions are shown in Table 2. The chamber pressure was set at 2 Torr $\left(\mathrm{H}_{2} \mathrm{O}_{(\mathrm{g})}\right)$ or 4 Torr (He) and the chamber was automatically evacuated and flooded with the imaging gas several times to obtain a pure atmosphere. Initial imaging parameters were obtained by taking

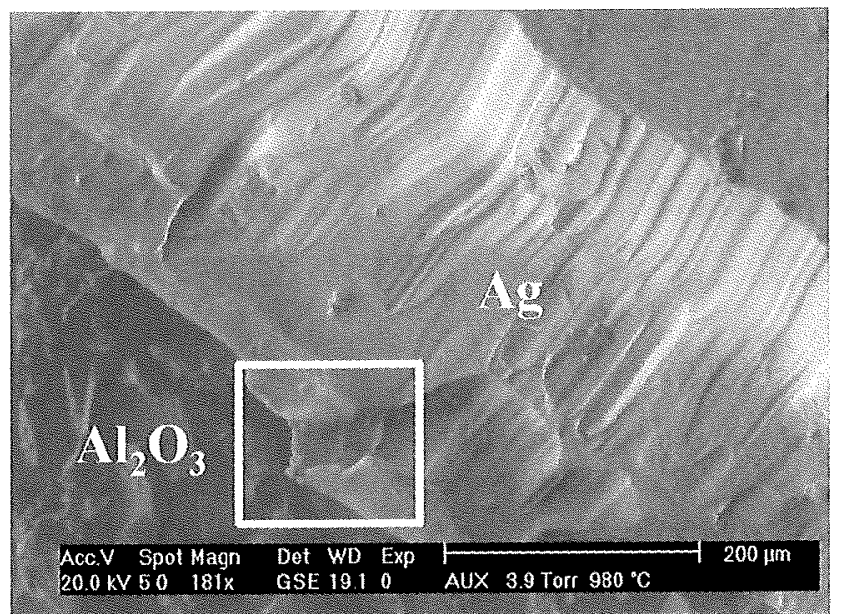

Fig. 2 Secondary electron image of the preform surface $\left(\mathrm{Al}_{2} \mathrm{O}_{3}\right)$ at $980^{\circ} \mathrm{C}$. The silver $(\mathrm{Ag})$ wire still has its original form. The highlighted area (white box) is shown in detail in Figs 3-5.

images at low resolution with the heat shield removed. A sample section, where both metal and ceramic surface were visible, was focused and the image optimized at a high magnification at room temperature.

At temperatures $>400^{\circ} \mathrm{C}$ the image contrast faded due to thermal effects. The contrast was enhanced by adjusting simultaneously the sample bias (from negative (enhance electron emission) to positive (suppress emission of thermal electrons)), shield bias, contrast and brightness. Drifting, probably due to thermal expansion, was observed, but usually stopped when the temperature was kept constant for a few minutes. Imaging at higher temperatures, especially in the range of $850-1000^{\circ} \mathrm{C}$, required continuous adjustment of the imaging parameters. The image contrast decreased continuously with temperature. Manual and stepwise increase of the temperature instead of automatic ramping was the best procedure to obtain a stable image. At higher temperatures, an increase in spot size and gas pressure helped to improve the image quality. Once a temperature of $\sim 1200^{\circ} \mathrm{C}$ was reached, the contrast of the image was quite low, but stable.

For experiments with silver (melting point: $962^{\circ} \mathrm{C}$ ), helium was used as the imaging gas. Liquid silver has a wetting angle on alumina that depends strongly on the oxygen fugacity $\left(\mathrm{fO}_{2}\right)$. At a temperature of $982^{\circ} \mathrm{C}$ and for low $\mathrm{fO}_{2}$ in the order of $10^{-12}$, liquid silver is non-wetting with a contact angle of $128^{\circ}$. With increasing oxygen fugacity the wetting angle decreases to reach a value of slightly $<90^{\circ}$ [8]. Despite the high wetting angle, silver infiltrates porous $\mathrm{Al}_{2} \mathrm{O}_{3}$ preforms in the presence of an activator, such as Ti [9].

Wetting behaviour of silver on $\mathrm{Al}_{2} \mathrm{O}_{3}$ powder bed containing $T i$ particles observed in the ESEM. At temperatures between 20 and $800^{\circ} \mathrm{C}$, the surface of the silver did not show any change (Fig. 2). The thermocouple reading at the first signs of melting (Fig. 3) was $1060^{\circ} \mathrm{C}$, i.e. $100^{\circ} \mathrm{C}$ above the melting 


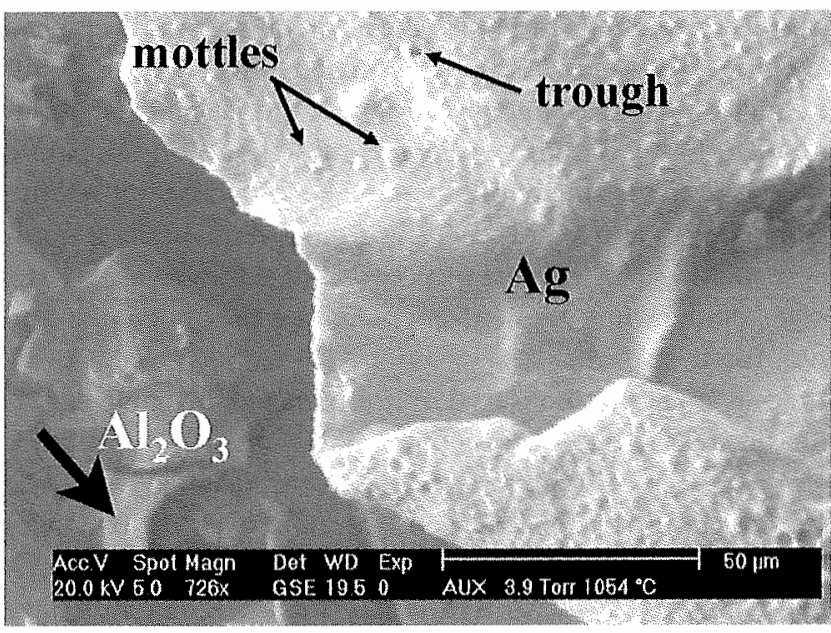

Fig. 3 Secondary electron image of the sample at $1054^{\circ} \mathrm{C}$. The $\mathrm{Ag}$ shows first signs of melting, small mottles and troughs evolve from the surface. The big black arrow marks the alumina grain used to determine the relative movement of the melt front (see Fig. 5).

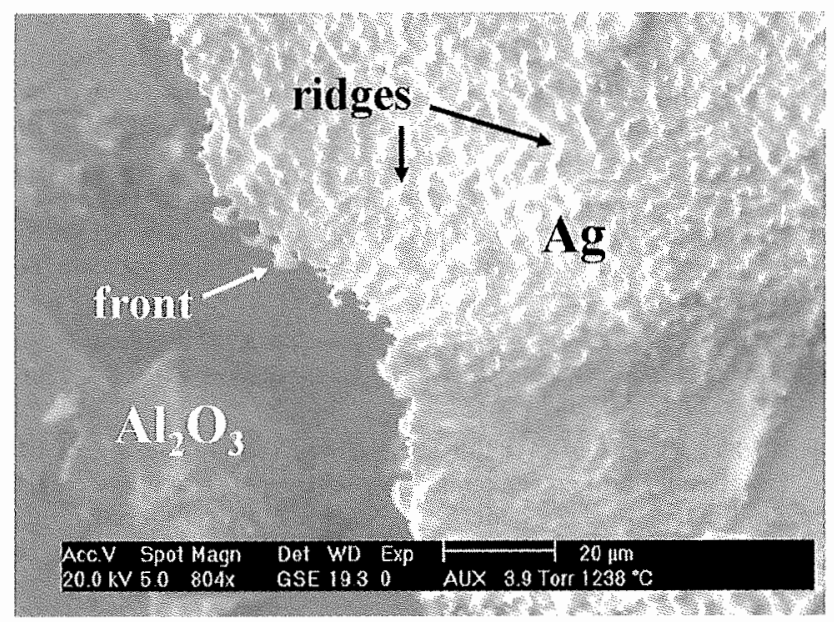

Fig. 4 Secondary electron image at $1238^{\circ} \mathrm{C}$. The $\mathrm{Ag}$ front shows more irregular features. The peaks on the $\mathrm{Ag}$ surface have grown into ridges.

temperature of silver. This discrepancy can be explained by the position of the thermocouple that is closer to the heating coils than to the sample surface as well as by diffusive losses and bad thermal contact of the metal with the ceramic matrix. Thus, the temperature at the thermocouple was higher than the temperature of the sample. The following temperatures are those as measured by the thermocouple. Small mottles formed on the silver surface and grew with increasing temperature into small ridges and troughs (Figs 3 and 4).

In other experiments, better contact between the silver and the underlying preform was achieved. However, a temperature gradient of $\geq 40^{\circ} \mathrm{C}$ remained due to the experimental set-up. At the onset of melting the liquid metal retreated, leaving small finger-like protrusions behind (Fig. 4). With increasing temperature and time, most of the fingers disappeared (Fig. 5).

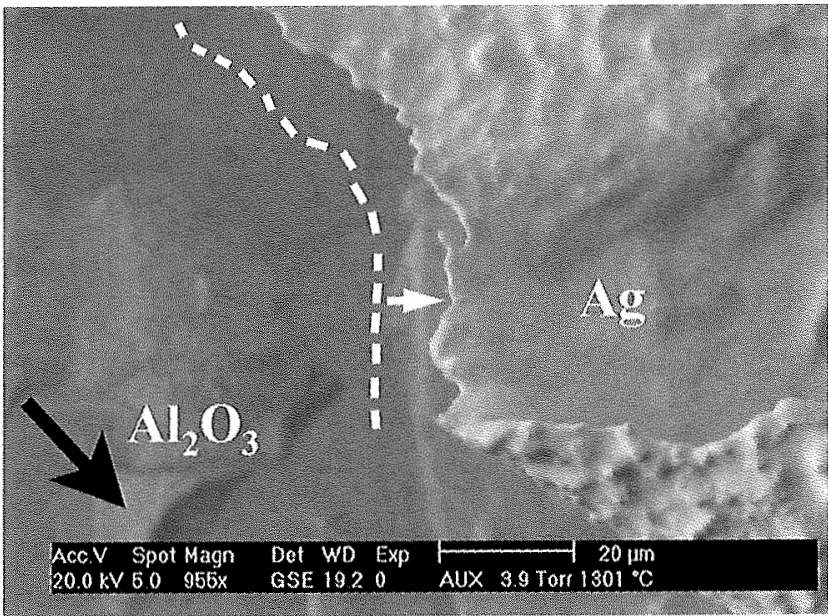

Fig. 5 Secondary electron image of the sample surface at $1301^{\circ} \mathrm{C}$. The white line indicates the location of the $\mathrm{Ag}$ front at $1054^{\circ} \mathrm{C}$ (Fig. 3). It can be seen that the front is moving (indicated by the white arrow) with increasing temperature, it is not spreading but shrinking until suddenly complete dewetting occurs and Ag spheres form. The movement of the front was determined relative to the alumina grain indicated above by the black arrow (see Fig. 3).

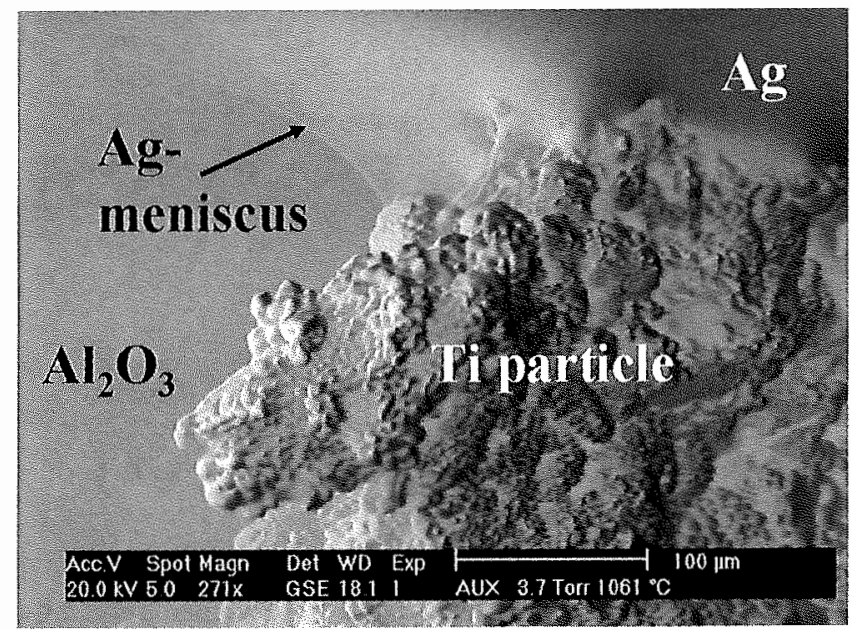

Fig. 6 Secondary electron image at $1061^{\circ} \mathrm{C}$. The Ag melt stays in contact with $\mathrm{Ti}$ particles on the $\mathrm{Al}_{2} \mathrm{O}_{3}$ preform surface.

The stable protrusions (Fig. 6) were attached to Ti particles or otherwise fixed due to surface roughness and edges on the alumina surface. The melt bridges between the main melt body and the pinning particles can be up to $50 \mu \mathrm{m}$ long. At temperatures above $\sim 1100^{\circ} \mathrm{C}$, a sudden contraction of the silver melt to a multitude of spheres was observed. Only the Ti particles remained partially wetted by the melt (Fig. 7).

The sudden change in surface tension might be due to the low oxygen fugacity of the imaging gas (He). The silver surface, despite the initial cleaning, is probably still slightly oxidized. At the beginning of melting this oxygen dissolved in the liquid silver could lower the wetting angle. Degassing of oxygen will dramatically increase the wetting angle. 


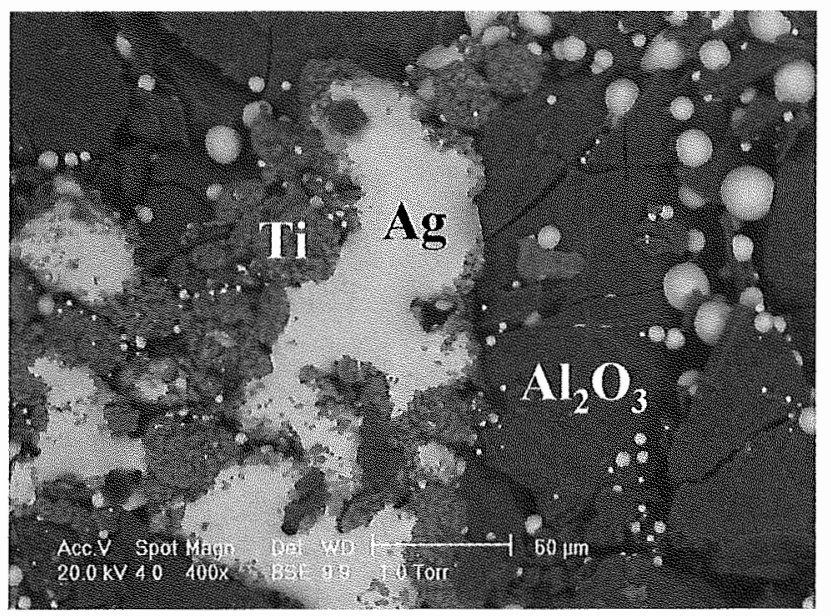

Fig. 7 Backscattered electron image of Ag after cooling to ambient temperature. Only partial wetting of $\mathrm{Ti}$ particles was achieved and no wetting by silver occurred on the $\mathrm{Al}_{2} \mathrm{O}_{3}$ particles of the preform.

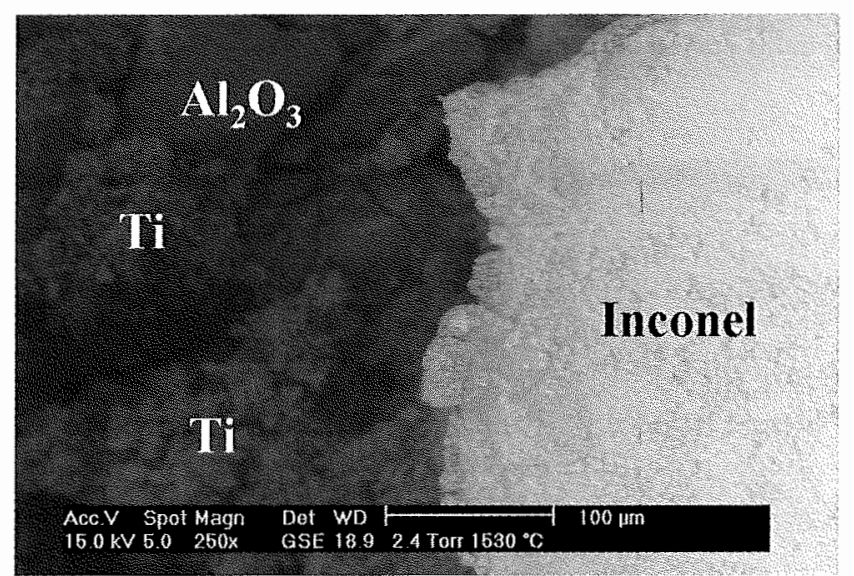

Fig. 8 Secondary electron image of Inconel at $1530^{\circ} \mathrm{C}$ on the preform. No complete melting was observed.

Similar morphology changes due to bubble formation and subsequent degassing were also observed by Millar et ai. in silver catalysts under different oxygen-containing atmospheres at temperatures of $>530^{\circ} \mathrm{C}$ [10].

The inability to infiltrate the $\mathrm{Al}_{2} \mathrm{O}_{3}$ powder bed with silver within the ESEM is probably due to the non-wetting liquid and the elevated pressure within the ESEM sample chamber. Tests in a conventional high-vacuum furnace (Super VII, Centorr Vacum Industries) have shown that silver infiltrated well under high vacuum conditions $\left(\leq 3 \times 10^{-4}\right.$ Torr), but not at pressures of $4 \times 10^{-2}$ Torr.

Infiltration experiments with Inconel. For these experiments, $\mathrm{H}_{2} \mathrm{O}_{(\mathrm{g})}$ was used as the imaging gas since Inconel could not be infiltrated successfully in a He atmosphere in a conventional furnace. Inconel with a melting point of $1350^{\circ} \mathrm{C}$ was first melted on the same type of $\mathrm{Al}_{2} \mathrm{O}_{3}$ preform as previously in the silver experiments. The temperature was raised at $10^{\circ} \mathrm{C} \mathrm{min}{ }^{-1}$. At $1530^{\circ} \mathrm{C}$, Inconel was still not completely melted. In Figure 8 the metal shows the typical creeping of its margins as it approaches its melting point. Inconel was then heated directly in a MgO crucible (without preform) to see if improved heat conduction of the substrate could lead to melting of the Inconel. Despite the temperature being $150^{\circ} \mathrm{C}$ above the melting point of Inconel, a complete melting of the metal piece was not achieved due to the large temperature gradient between the thermocouple and the sample surface.

It was possible to observe in situ melting and melt migration of silver due to wetting on a Ti-activated $\mathrm{Al}_{2} \mathrm{O}_{3}$ preform. Temperatures as high as $1530^{\circ} \mathrm{C}$ were reached with the commercial hot stage and good secondary electron images up to these temperatures were obtained using different imaging gases $\left(\mathrm{H}_{2} \mathrm{O}_{(g)}\right.$, He) and gas pressures. The hot stage combined with the possibility to use different gas atmospheres makes the ESEM a very powerful tool for in situ high temperature investigations of wetting processes.

\section{References}

I Englisch C (1999) Reaktionen und Benetzung bei der Herstellung von siC/ Bronze-Kompositen über Schmelzinfiltration. [Reaction and Wetting during Production of SiC/Bronze Composites by Melt Infiltration.] (Doctoral thesis, EPF-Lausanne, Switzerland.)

2 Krauss G, Kuebler J, and Trentini E (2002) Preparation and properties of pressureless infiltrated $\mathrm{SiC}$ and AlN particulate reinforced metal ceramic composites based on bronze and iron alloys, Mater. Sci. Eng. A 337: 315-322.

3 Krauss G (2001) Schadenstolerante Keramik-Metall-Verbundwerkstoffe. [Failure-Tolerant Ceramic Metal Composites.] (Report EUREKA 1800 / KTI 3734.1.)

4 Kuebler J, Lemster K, Graule T, Minghetti T, and Schelle C (2003) Eisenbasislegierung/Oxidkeramik-MMCs durch reaktive Schmelzinfiltration. [Fe-base alloy/oxide ceramic MMCs by reactive melt infiltration.] In: Verbundwerkstoffe, ed. Degischer H P, pp. 73-78, (Wiley-VCH, Weinheim).

5 Lemster K, Klotz U E, Fischer S, Gasser Ph, and Kuebler J (2004) Titanium as an activator material for producing MMCs by pressureless melt infiltration. In: Ti-2003 Science and Technology, eds Luetjering $G$ and Albrecht J, pp. 2523-2530, (Wiley-VCH, Weinheim).

6 Danilatos G D (1988) Foundations of environmental scanning electron microscopy. Adv. Electronics Elec. 71: 109-250.

7 Danilatos G D (1994) Environmental scanning electron microscopy and microanalysis. Mikrochim. Acta 114: 143-155.

8 Chatain D, Chabert F, Ghetta V, and Fouletier J (1994) New experimental setup for wettability characterization under monitored oxygen activity II, Wettability of sapphire by silver oxygen melts. J. Am. Ceram. Soc. 77: 197--201.

9 Fischer S (2003) Study of the Reaction Mechanism during Reactive Melt Infiltration Promoted by an Activator. (Diploma thesis, University of Fribourg, Switzerland.)

I0 Millar G J, Nelson M L, and Uwins P J R (1998) In situ observation of structural changes in polycrystalline silver catalysts by environmental scanning electron microscopy. J. Chem. Soc., Faraday Trans. 94: 2015-2023. 